\title{
COOLER BOX DENGAN THERMOELECTRIC COOLER DENGAN MONITORING SUHU BERBASIS LABVIEW DAN IOT
}

\author{
Muhammad Zola' ${ }^{1)}$, Livio Cahyadi'), Tossin Alamsyah ${ }^{3)}$ \\ ${ }^{1,2,3}$ Jurusan Teknik Elektro, Politeknik Negeri Jakarta, Kampus UI, Depok 16425, Indonesia \\ Email: ִalamsvah.pni@gmail.com
}

\begin{abstract}
The cooler box is used to keep food and beverage ingredients cool and fresh for a long time. The article presentation of the Thermoelectric Cooler (TEC) using at Cooler Box as an environmentally friendly cooling system in the cooler box. TEC is installed side by side with heat sink and colling fan which is given a voltage of 12 Volts so that the TEC produces cold temperatures which are used as cooler cooler boxes. The temperature of the TEC cooling results in the cooler box is detected by the DS18B20 Sensor with the Arduino Uno microcontroller. The entire system on the ATMega328 TEC-based TEC with DS18B20 sensor can be connected and coordinated well.

The minimum ATmega328 system works well as a data processor. DS18B20 can work according to its function of detecting temperature in the cooler box.

Basically this tool is a cooler box that utilizes the TEC as a cooling system along with temperature measurement by the DS18B20 Sensor.
\end{abstract}

Keywords: Cooler Box, TEC, Sensor DS18B20, Arduino Uno.

\begin{abstract}
ABSTRAK
Cooler box merupakan alat yang difungsikan untuk menjaga bahan makanan dan minuman agar tetap dingin dan segar dalam waktu yang lama. Penambahan sistem pendingin pada cooler box dapat dilakukan dengan memodifikasi bagian cooler box. Tujuan dari penelitian ini yaitu memanfaatkan Thermoelectric Cooler (TEC) sebagai sistem pendingin yang ramah lingkungan pada cooler box. TEC dipasang berdampingan dengan Heatsink dan Cooling Fan yang diberikan tegangan sebesar 12 Volt sehingga TEC menghasilkan suhu dingin yang dimanfaatkan sebagai pendingin cooler box. Suhu hasil pendinginan TEC pada cooler box dideteksi oleh Sensor DS18B20 dengan mikrokontroler Arduino Uno. Keseluruhan sistem pada TEC berbasis mikrokontroler ATMega328 dengan sensor DS18B20 dapat tersambung dan terkoordinasi dengan baik. Minimum sistem ATmega328 bekerja dengan baik sebagai pengolah data. DS18B20 dapat bekerja sesuai dengan fungsinya yaitu mendeteksi suhu dalam cooler box. Pada dasarnya alat ini adalah cooler box yang memanfaatkan TEC sebagai sistem pendingindisertai pengukuran suhu oleh Sensor DS18B20..
\end{abstract}

Kata Kunci: Cooler Box, TEC, Sensor DS18B20, Arduino Uno.

\section{PENDAHULUAN}

Fungsi Cooler box untuk menstabilkan berbagai macam makanan dan minuman agar tetap dingin sebelum diolah/dikonsumsi. Ada beberapa metode mendinginkan di dalam cooler box yaitu dengan memasukkan es batu atau didinginkan dengan bantuan freon. Alat pendingin ber-freon sebisa mungkin dihindari, karena kurang ramah lingkungan. Dampaknya negatif bagi lingkungan jika terus-menerus menggunakan freon. Box ber-freon lebih berat dan berukuran lebih besar. Oleh karena itu para pedagang kaki lima lebih memilih cooler box tanpa freon dibandingkan ber-freon. Suhu di dalam cooler box dipertahankan kestabilannya dengan penambahan es batu. Cooler box yang dingin dengan penambahan es batu tidak dapat bertahan lama. Penambahan es batu justru membuat cooler box menjadi lebih berat dan berair. Oleh karenanya muncul gagasan untuk memodifikasi cooler box yang dapat mendinginkan bahan makanan dengan memanfaatkan thermoelectric cooler.

Sistem pendingin dari efek listrik bertegangan rendah pada lempeng sejenis logam telah diimplementasikan oleh [3]. Bahan semikonduktor pada 
Thermoelectric Cooler (TEC) sesuai dengan efek peltier dapat dimanfaatkan sebagai perangkat pendingin. Bahan semikonduktor tersebut terdiri dari tipe $\mathrm{N}$ (negatif) dan tipe $\mathrm{P}$ (positif) diposisikan paralel secara termal. Ujung semikonduktor dilekatkan dengan lempeng pendingin berbahan tembaga/aluminium. Dua sisi TEC suhunya berbeda, yaitu sisi panas dan sisi dingin. Efek peltier pada TEC membuat panas disatu sisi (sisi panas), di sisi lain panas akan terserap hingga terasa dingin (sisi dingin). Jika sebuah elemen peltier dialiri arus listrik DC maka kedua sisi elemen ini akan menjadi panas dan dingin. Sisi dingin inilah yang dimanfaatkan sebagai pendingin dengan bantuan heatsink dan fan [1]. Sensor Dallas DS18B20 merupakan sensor pendeteksi suhu [2], yang memiliki keluaran data dalam bentuk digital. Arduino Uno dikoneksikan dengan sensor untuk program pendeteksian suhu.

\section{METODE PENELITIAN}

Perancangan Perangkat Keras Cooler Box Memanfaatkan Thermoelectric Cooler (TEC) ini terdiri dari sistem pendingin dan sistem pengukuran suhu. Sistem pendingin pada Cooler box ini menggunakan prinsip kerja TEC sebagai bahan semikonduktor yang terdiri dari tipe $\mathrm{P}$ dan tipe $\mathrm{N}$ yang jika diberikan sumber tegangan dan arus listrik sesuai referensinya maka terjadi perubahan suhu pada kedua sisinya yaitu sisi panas dan sisi dingin. Sisi dingin dimanfaatkan sebagai sistem pendingin pada cooler box. Sistem pengukuran suhu menggunakan sensor DS18B20 sebagai pendeteksi suhu cooler box. Hasil deteksi suhu dikirimkan ke mikrokontroler arduino untuk diproses. Realiasi sistem cooler box difokuskan pada instalasi modul sensor DS18B20, TEC, Mikrokontroler dan PC.
Langkah-langkah solusi permasalahan, untuk perancangan system presensi finger print mengacu pada:

Flowchart (Gambar1) uang memuat diagram alir system identifikasi, buka/ tutup pengunci solenoid pada model pintu, dan desain perancangan penampil dengan web cloud.

Blok Diagram (Gambar 2); terdiri dari komponen-komponen dan modul-modul pendukung system. Yaitu: input dari sensor, pemroses data input dengan mikrokontroler, dan penampil data sebagai output system.

Menurut Joyner R. Oroh, dkk. (2014), empat pola dasar Dermatoglyphic tentang sidik jari adalah; Whorl atau Swirl, Arch, Loop, dan Triradius. Pola lainnya, merupakan variasi dan kombinasi keempatnya. Setiap orang mungkin memiliki Whorl, Arch, atau Loop di setiap ujung jari yang berbeda, atau mungkin Triradius pada gunung dari Luna dan di bawah setiap jari. Mayoritas orang mempunyai pola dua Whorl atau Loop di jari tangan lainnya. Cara kerja identifikasi dengan metode optical scanning pola jari (Gambar 3), sehingga setiap sidik jari sesorang berbeda.

\section{1) Perancangan Sistem pada Cooler Box}

Nama Alat yaitu Cooler Box memanfaatkan Thermoelectric Cooler (TEC) dengan Sistem Pemonitor Suhu Berbasis LabVIEW dan IoT

Fungsi Sistem yaitu menjaga bahan makanan/minuman agar tetap dingin serta memonitor suhu dengan LabVIEW dengan memanfaatkan Thermoelectric Cooler (TEC) sebagai aktuator.

Cara Kerja yaitu makanan atau minuman yang akan dijaga kestabilannya agar tetap dingin diletakkan di dalam Cooler Box. Thermoelectric Cooler yang aktif akan menurunkan kondisi suhu bagian dalam Cooler Box. Data hasil 
pendeteksian suhu oleh sensor DS18B20 dikonversikan ke dalam bentuk digital dan ditampilkan berupa suhu per derajat celcius. Gambar 1 menunjukkan blok diagram sistim cooler.

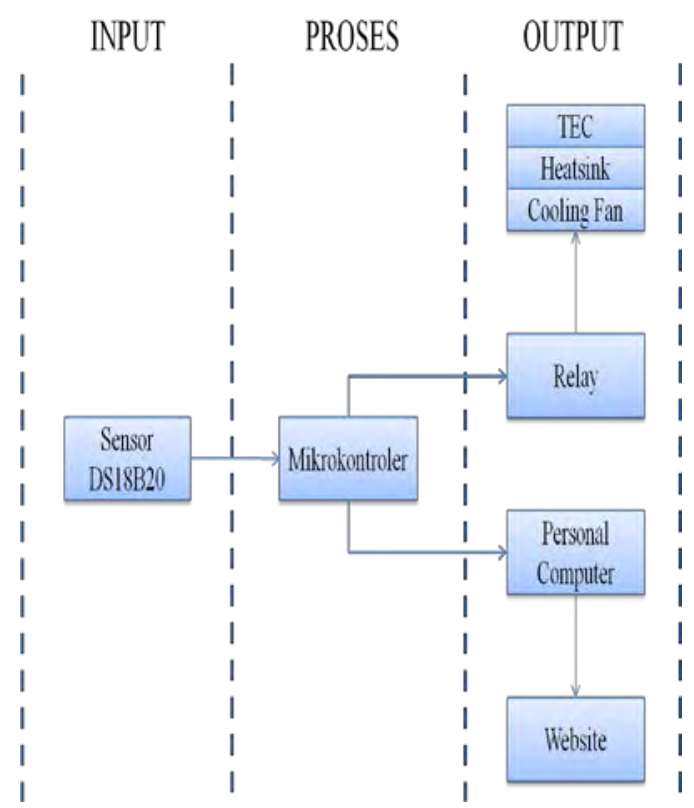

Gambar 1. Blok Diagram Sistim

Keterangan :

INPUT

a) Sumber Tegangan memberikan tegangan sebesar 12 Volt DC ke koneksi TEC dan Cooling Fan.

b) Sensor DS18B20 mendeteksi suhu yang akan diproses oleh mikrokontroler.

\section{PROSES}

Mikrokontroler mengolah data dari keluaran sinyal analog sensor menjadi sinyal digital kemudian hasilnya diproses pada personal computer

\section{OUTPUT}

a) TEC-Heatsink-CoolingFan berfungsi untuk menurunkan kondisi suhu.

b) Personal Computer mengolah dan menampilkan data suhu $\left({ }^{\circ} \mathrm{C}\right)$ hasil deteksi sensor.

Flow chart dari pola kerja mesin cooler adalah sebagai berikut;

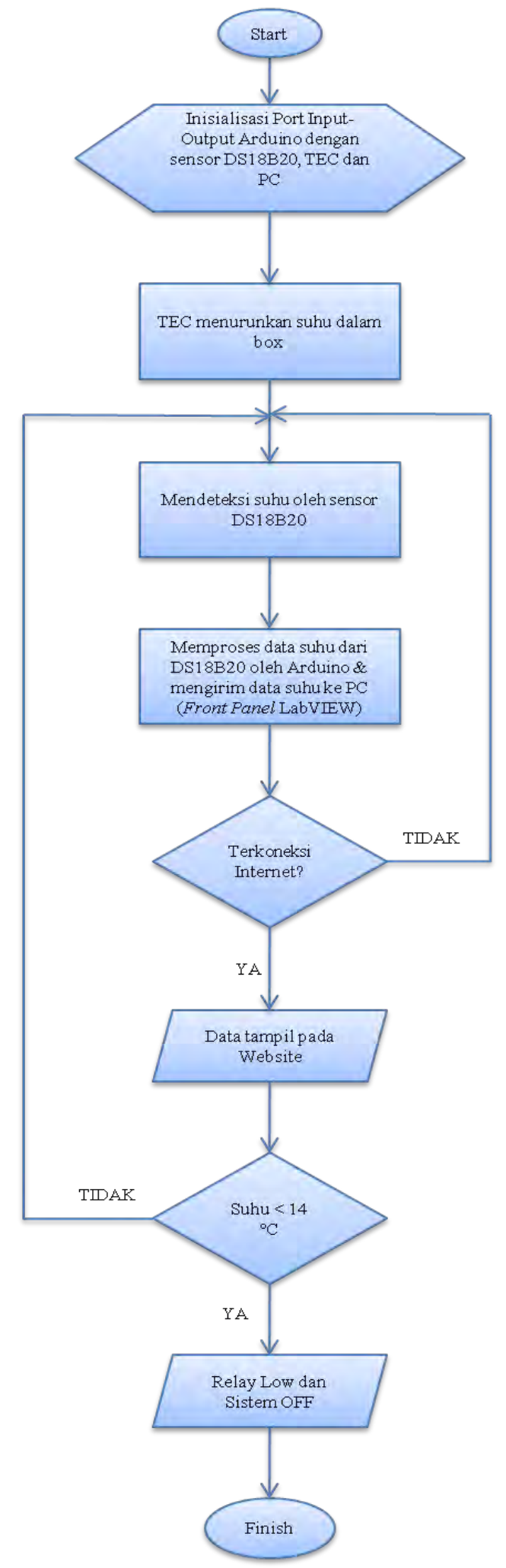

Gambar 2 . Flowchart Sistim Kerja Cooller

Rangkaian kelistrikan dari cooler box sistim dapat ditunjukkan seperti Gambar 3 , berikut. 


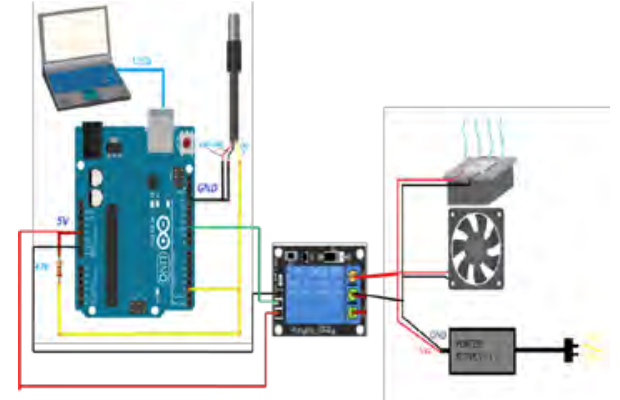

Gambar 3. Wiring diagram Cooler Box.

Pada wiring diagram sistem pengukuran suhu (a), data sensor DS18B20 dikoneksikan pada pin 2 mikrokontroler Arduino Uno untuk memproses suhu terdeteksi. Data dihubungkan pada tegangan $5 \mathrm{~V}$ arduino dengan resistor senilai $4.7 \mathrm{k} \Omega$. Vdd dan GND digabungkan secara "One Wire" pada pin GND Arduino Uno. Mikrokontroler dikoneksikan pada PC melalui port USB untuk mengkomunikasikan kedua perangkat. Wiring diagram sistem pendingin (b) dilakukan untuk mengaktifkan sistem pendingin dengan koneksi TEC, Heatsink dan Cooling Fan. Keseluruhan perangkat dikoneksikan pada sumber tegangan 12 VDC

\section{HASIL DAN PEMBAHASAN}

\section{1) Thermoelectric Cooler (TEC)}

TEC sebagai komponen pendingin pada wadah box. Ketika TEC diberikan tegangan DC (arus searah) salah satu sisinya menjadi panas, sementara sisi yang lainnya menjadi dingin, untuk memaksimalkan proses pendinginan [Munib Ahsani dan Agung Prijo, 2015], sisi panas Thermoelectric Cooler (TEC) harus diturunkan serendah mungkin dengan heat sink, cooling fan dan Thermal pasta (Gambar 1.1).

Ketika dua konduktor dihubungkan kontak listrik, elektron akan mengalir dari satu konduktor yang mempunyai elektron kurang terikat ke konduktor yang mempunyai elektron yang lebih terikat. Alasan yang mudah untuk hal ini adalah tingkat perbedaan Fermi antara dua konduktor.Perbedaan Fermi adalah istilah yang digunakan untuk menggambarkan bagian atas kumpulan tingkat energi elektron pada suhu nol absolut. Konsep ini berasal dari statistik Fermi-Dirac.Konsep energi Fermi adalah konsep yang sangat penting untuk memahami sifat listrik dan termal pada benda padat. Kedua proses listrik dan termal biasanya melibatkan energi elektron.Ketika dua konduktor dengan tingkat Fermi yang berbeda digabungkan, elektron akan mengalir dari konduktor dengan tingkat yang lebih tinggi ke tingkat yang lebih rendah, hingga perubahan potensial elektrostatik membawa dua tingkat Fermi menjadi nilai yang sama.

Bahan semikonduktor ThermoElectric yang paling sering digunakan saat ini adalah Bismuth Telluride yang telah diolah untuk menghasilkan blok atau elemen yang memiliki karakteristik individu berbeda yaitu $\mathrm{N}$ dan $\mathrm{P}$. Bahan Thermo-Electriclainnya termasuk Timbal Telluride, Silicon Germanium dan Bismuth-Antimony adalah paduan bahan yang dapat digunakan dalam situasi tertentu. Namun, Bismuth Telluride adalah bahan terbaik dalam hal pendinginan.

Bismuth Telluride memiliki dua karakteristik yang patut dicatat. Karena struktur kristal, Bismuth Telluride sangat anisotropic. Perilaku anisotropic perlawanan lebih besar daripada konduktivitas termalnya. Sehingga anisotropic ini dimanfaatkan untuk pendinginan yang optimal. Karakteristik lain yang menarik dari Bismuth Telluride adalah kristal Bismuth Telluride terdiri dari lapisan heksagonal atom yang sama

Gambar 4 menunjukkan bentuk dari komponen TEC. 


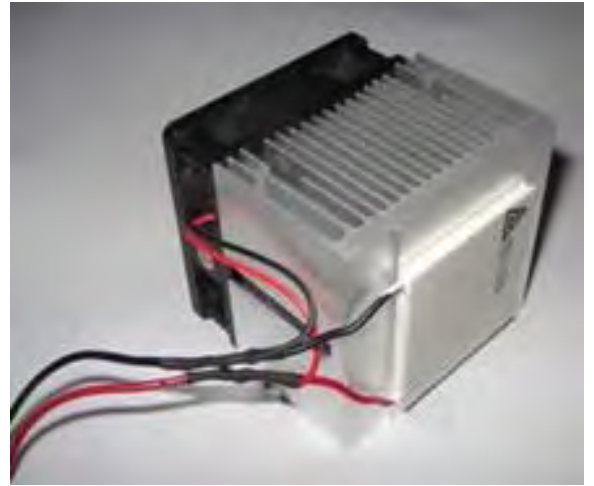

Gambar 4

TEC, Heatsink, dan Cooling Fan

\section{2) Sensor DS18B20}

Sensor DS18B20 merupakan suatu komponen elektronika yang dapat menangkap perubahan temperatur lingkungan [6], kemudian mengkonversinya menjadi besaran listrik. Tegangan sumber untuk sensor DS18B20 adalah 3V sampai 5.5V. Sensor ini juga dapat mengukur suhu pada kisaran -55 sampai $125^{\circ} \mathrm{C}$

Fitur dari sensor suhu DS18B20 yaitu antarmuka hanya menggunakan satu kabel sebagai komunikasi(menggunakan protokol one wire),setiap sensor memiliki kode pengenal unik 64-bit tertanam di onboard ROM dan kemampuan multidrop yang menyederhanakan aplikasi penginderaan suhu terdistribusi serta tidak memerlukan komponen tambahan.

Penggunannya bisa dalam lingkungan kendali termostatis, sistem industry ,produk rumahan, termometer atau sistem apapun yang memerlukan pembacaan suhu.

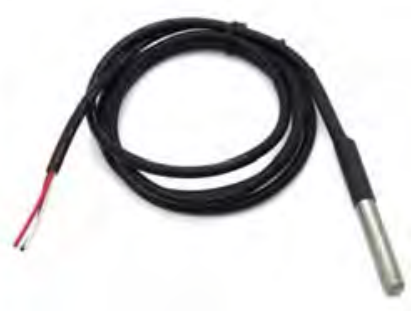

Gambar 5 Sensor DS18B20

\section{3) Arduino Uno dan Relay}

Arduino Uno merupakan sebuah board mikrokontroler yang didasarkan pada ATmega328. Arduino Uno memuat semua yang dibutuhkan untuk menunjang mikrokontroler, mudah menghubungkannya ke sebuah komputer/laptop dengan sebuah kabel USB [5]. Sensor Dallas DS18B20 sebagai sensor pendeteksi suhu dan Relay yang dapat di program untuk mengontrol dan dapat dikoneksikan dengan Arduino Uno (Gambar 1.3). Arduino Uno mengkonversi sinyal analog dari sensor yang kemudian diprogram melalui aplikasi labview.

Gambar 6 menunjukkan gambar rankaian sistim cooler box.

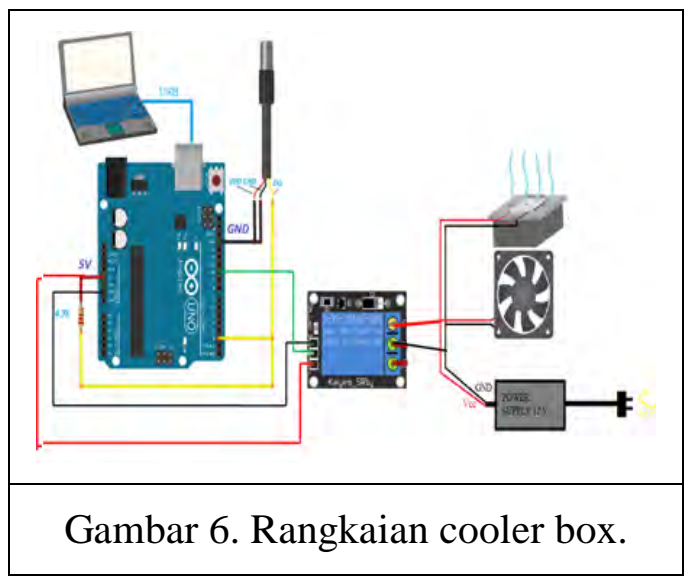

Perancangan Perangkat Keras Cooler Box Memanfaatkan Thermoelectric Cooler (TEC) ini terdiri dari sistem 
pendingin dan sistem pengukuran suhu. Sistem pendingin pada Cooler box ini menggunakan prinsip kerja TEC sebagai bahan semikonduktor yang terdiri dari tipe $\mathrm{P}$ dan tipe $\mathrm{N}$ yang jika diberikan sumber tegangan dan arus listrik sesuai referensinya maka terjadi perubahan suhu pada kedua sisinya yaitu sisi panas dan sisi dingin. Sisi dingin dimanfaatkan sebagai sistem pendingin pada cooler box. Sistem pengukuran suhu menggunakan sensor DS18B20 sebagai pendeteksi suhu cooler box. Hasil deteksi suhu dikirimkan ke mikrokontroler arduino untuk diproses. Realiasi sistem cooler box difokuskan pada instalasi modul sensor DS18B20, TEC, Mikrokontroler dan PC.

Data hasil deteksi sensor diinputkan ke mikrokontroler dan dikonversi untuk diambil data suhu per detik. Pengujian dilakukan dengan mengukur suhu cooler box menggunakan sensor dan termometer digital. Data suhu yang terdeteksi melalui sensor dan termometer digital dibandingkan perubahannya dalam beberapa waktu.

Hasil pengamatan dengan menggunakan processing visual arduino terhadap sensor untuk mengukur suhu dengan meletakan sensor dalam cooler box. Tampilan suhu pada serial arduino menunjukkan nilai suhu per derajat celcius. Data suhu yang diamati berlangsung selama 8 menit untuk mencapai titik terendah. Nilai suhu yang ditampilkan pada termometer digital adalah $1,2{ }^{\circ} \mathrm{C}$

\section{1) Analisis Data}

Pengujian dilakukan untuk mendokumentasikan suhu yang dihasilkan pada permukaan TEC. Suatu pengujian perlu dilakukan untuk memastikan TEC dalam kondisi baik. Data suhu yang terukur pada termometer dicatat setiap menit.
Hasil pengujian berupa grafik pengukuran suhu permukaan TEC (Gambar 7) menunjukkan pada kondisi awal diaktifkan sebesar $29,3{ }^{\circ} \mathrm{C}$ sampai suhu terendah yang dicapai adalah $1,2^{\circ} \mathrm{C}$ yang berlangsung selama 8 menit.

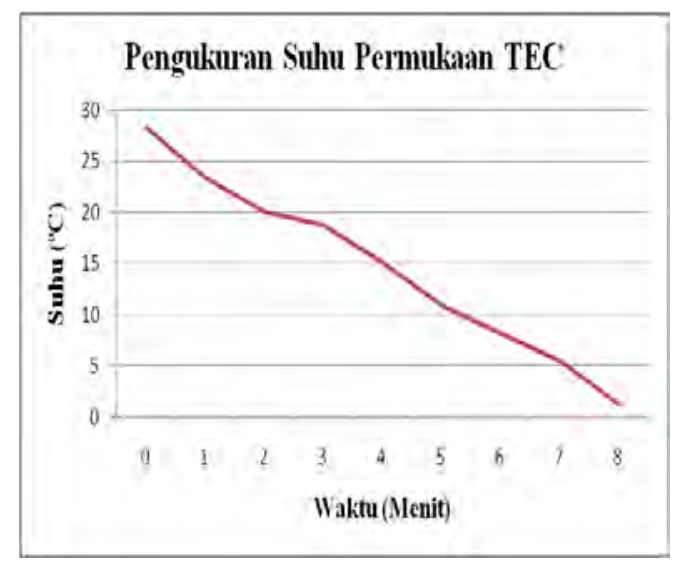

Gambar 7 Grafik Pengukuran Suhu Permukaan TEC

Data lengkap kinerja Cooler box dapat dilihat pada tabel di halaman paling akhir, Tabel 1 Kinerja.

\section{a) Analisa Data Pengukuran Suhu Pertama}

Pengujian dan pengambilan data pertama dilakukan pada kondisi ruang tertutup dengan suhu ruang sebesar 32,7 ${ }^{\circ} \mathrm{C}$. Nilai pengukuran suhu oleh sensor menunjukan selisih angka sebesar $1^{\circ} \mathrm{C}$ pada menit 0 atau detik pertama sistem diaktifkan.

Grafik pengukuran suhu pertama (Gambar 8) menunjukkan alur pengukuran suhu oleh termometer dan sensor. Selisih pengukuran cukup besar terjadi pada menit 0 sedangkan pada menit 7 tidak terjadi perbedaan pengukuran suhu oleh termometer dan sensor. 


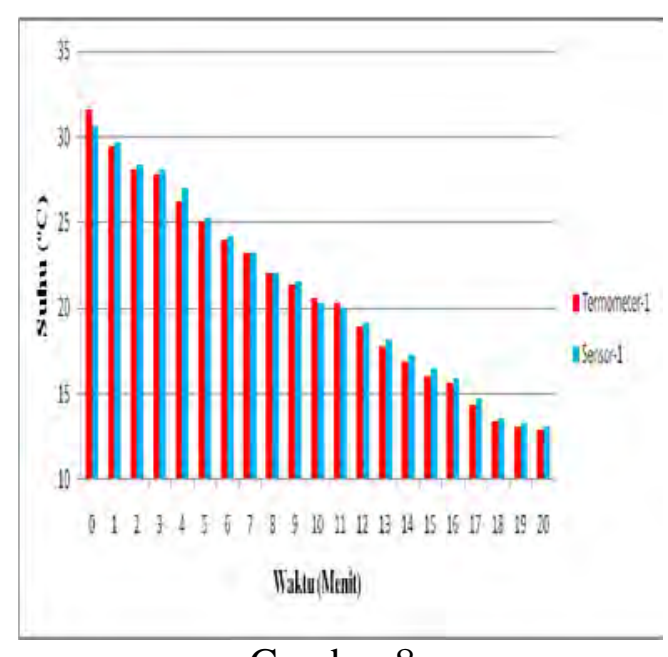

Gambar 8.

Grafik Pengukuran Suhu

$\%$ Error

$=\frac{(\text { Total Nilai yang terbaca }- \text { Total Nilai Sebenarnya })}{\text { Total Nilai Sebenarnya }}$

$\times 100 \%$

$$
\begin{gathered}
\% \text { Error }=\frac{(442-439,1)}{439,1} \\
\times 100 \% \\
\% \text { Error }=0,66 \%
\end{gathered}
$$

Hasil pengukuran suhu oleh sensor untuk berada di range eror yang masih bisa ditoleransi yakni $\pm 2 \%$. Hanya saja nilai pengukuran suhu pada setiap menitnya sering tidak stabil.

Hasil pengukuran yang lengkap dapat dilihat pada Gambar 9 dihalaman terakhir.

\section{KESIMPULAN}

Pengukuran suhu pada permukaan dingin TEC dapat mencapai suhu terendah sebesar $1,2{ }^{\circ} \mathrm{C}$ tetapi dalam penerapannya dengan penambahan aluminium dan fan pada permukaan dinginnya memerlukan waktu yang lama untuk menurunkan suhu ruangan Cooler Box dan hanya mencapai suhu ruangan sebesar $12,9-13,4{ }^{\circ} \mathrm{C}$.

Sistem pengukuran suhu oleh sensor sudah dapat dimanfaatkan dan dikembangkan meski terdapat error sebesar $0,66 \%$ dan $1,48 \%$ pada setiap percobaan. Suhu lingkungan berpengaruh terhadap suhu Cooler Box.

\section{UCAPAN TERIMAKASIH}

Ucapan terima kasih disampaikan untuk P3M PNJ yang telah mendanai sehingga penelitian ini sebagai bagian dari Tugas Akhir.

\section{DAFTAR PUSTAKA}

[1.]Amrullah. 2014. "Penerapan Termoelektrik Ganda pada Mesin Pendingin Air Minum sebagai Solusi Penghematan Energi” Jurnal Teknologi Terapan, Volume 1, Nomor 1, November 2015, hlm 42-48.

[2.]Joessianto Eko Poetrol dan Catur Rakhmad Handoko. 2013. "Analisis Kinerja Sistem Pendingin Arus Searah Yang Menggunakan Heatsink Jenis Extruded Dibandingkan Dengan Heatsink Jenis Slot”. Jurnal Teknik Mesin Vol. 21, No. 2, Oktober 2013, hlm 178-188.

[3.] Mhd. Idris, Indra Jaya. 2014. "Pengembangan Data Logger Suhu Air Berbiaya Rendah (Development of Low Cost Water Temperature Data Logger)”. Jurnal Teknologi Perikanan dan Kelautan Vol. 5, No. 1, Mei 2014, hal. 95-108.

[4.]Munib Ahsani, Agung Prijo. 2015. "Rancang Bangun Pendingin Ruangan Portable Dengan Memanfaatkan Efek Perbedaan Suhu Pada Thermo Electric Cooler (TEC)”. Jurnal Rekayasa Mesin. Vol. 3, No.1, Tahun 2015, hal. 100-109. 
[5.]Kurnia, Yoga Alif. 2016. "Perbandingan Kualitas Antar Sensor Suhu dengan Menggunakan Arduino Pro Mini.” Jurnal Narodroid Vol. 2, No.2, Juli 2016, hal.145-150.

[6.] Ichwan, Muhammad. 2014. "Pembangunan Prototipe Sistem Pengendalian Peralatan Listrik Pada Platform Android”. Jurnal Informatika Vol. 4, No. 1, April 2013, hal. 13-25.

[7.]Agus Pracoyo, Tossin Alamsyah ,2011 "Rancang Bangun Dan Pengujian Devais Peripheral Input/Output ( $\mathrm{P} \mathrm{I} / \mathrm{O}$ ) Berbasis Universal Serial Bus (USB)”, Jurnal Poli-Teknologi , Vol 10, No. 2 , 2011.

[8.]Tossin Alamsyah1, Desmond Amos dan Hafizh Nurul Istiqomah, "Speech Recogniton Dengan Platform Labview Dan Analisis Menggunakan Matlab.” Jurnal Poli-Teknologi , Vol 16, No. 2 , 2017 
Tabel 1 Data Hasil Pengukuran Suhu per Menit

\begin{tabular}{ccccc}
\hline \multirow{2}{*}{ Waktu (Menit) } & \multicolumn{4}{c}{ Pengukuran Suhu $\left({ }^{\circ} \mathrm{C}\right)$} \\
\cline { 2 - 5 } & \multicolumn{3}{c}{ Ke-1 } & \multicolumn{3}{c}{ Ke-2 } \\
\cline { 2 - 5 } Termometer & Sensor & Termometer & Sensor \\
\hline 0 & 31,6 & 30,6 & 32,1 & 31,3 \\
1 & 29,5 & 29,6 & 29,7 & 30,9 \\
2 & 28,1 & 28,4 & 28,3 & 29,2 \\
3 & 27,8 & 28,1 & 27,6 & 28,1 \\
4 & 26,3 & 27,0 & 26,2 & 27,0 \\
5 & 25,1 & 25,3 & 25,4 & 25,9 \\
6 & 24,0 & 24,2 & 24,2 & 24,7 \\
7 & 23,2 & 23,2 & 23,4 & 23,6 \\
8 & 22,0 & 22,1 & 22,3 & 22,7 \\
9 & 21,4 & 21,5 & 21,7 & 21,9 \\
10 & 20,6 & 20,3 & 20,1 & 20,6 \\
11 & 20,3 & 20,0 & 19,3 & 19,5 \\
12 & 19,0 & 19,1 & 18,8 & 18,9 \\
13 & 17,6 & 18,2 & 17,9 & 18,3 \\
14 & 16,9 & 17,3 & 17,5 & 18,0 \\
15 & 16,0 & 16,5 & 17,1 & 17,5 \\
16 & 15,7 & 15,9 & 16,5 & 16,4 \\
17 & 14,4 & 14,7 & 15,3 & 15,4 \\
18 & 13,4 & 13,6 & 14,6 & 14,7 \\
19 & 13,1 & 13,3 & 13,7 & 13,6 \\
20 & 12,9 & 13,1 & 13,3 & 13,4 \\
\hline
\end{tabular}

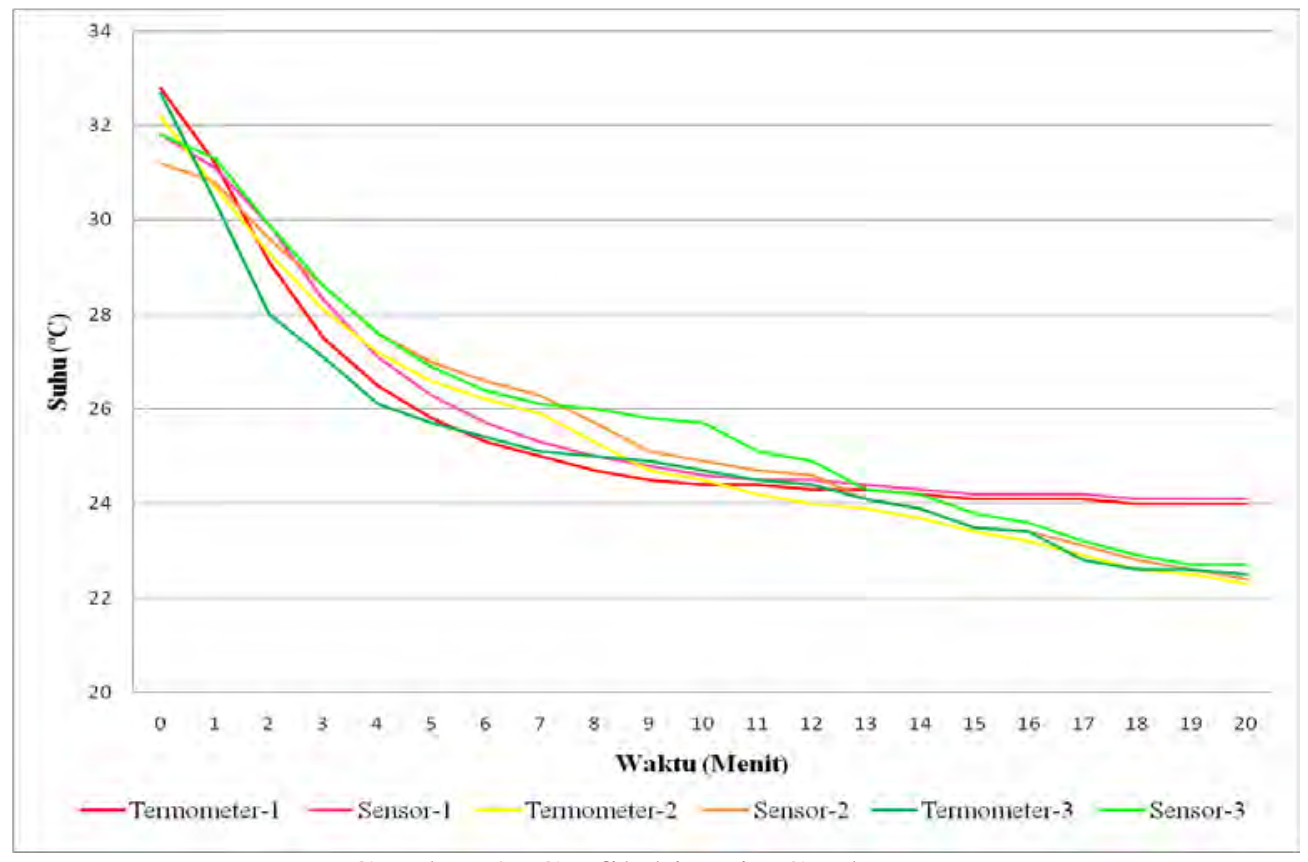

Gambar 8. Grafik kinerja Cooler Box. 
Muhammad Zola, Livio Cahyadi, Tossin Alamsyah, Cooler Box dengan... 